\title{
Diaphragmatic Bleb Complicated Hydrothorax in Peritoneal Dialysis
}

\author{
Han-Bin Wang ${ }^{1}$, Chien-Chang $\mathrm{Kao}^{2}$, Kuo-Feng $\mathrm{Hsu}^{2}$, Ming-Hsin $\mathrm{Yang}^{2}$, Hui-Ching $\mathrm{Yu}^{3}$ \\ and Jen-Chih Chen ${ }^{2}$
}

Key words: diaphragmatic bleb, hydrothorax, peritoneal dialysis

(Inter Med 48: 1333-1334, 2009)

(DOI: 10.2169/internalmedicine.48.2326)

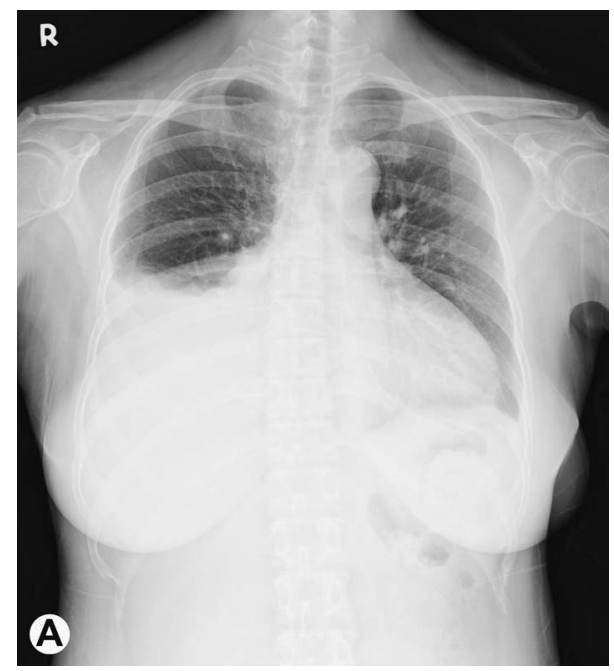

Picture 1A. Chest X-ray showing massive right side pleural effusion before video-assisted thoracoscopic surgery (VATS).

A 47-year-old woman had a two-year history of lupus nephritis and end-stage renal disease with continuous ambulatory peritoneal dialysis (CAPD). Soon after starting CAPD she developed dyspnea, nausea, and vomiting for 4 days. A chest X-ray revealed a massive right-side pleural effusion (Picture 1A). She underwent emergency thoracocentesis and pleural fluid analysis showed that it was transudative in character with high glucose levels. She temporarily received hemodialysis rather than CAPD. One month later, she resumed CAPD but this failed with recurrent right-side hydrothorax. She underwent video-assisted thoracoscopic surgery (VATS) that showed a right diaphragm bleb about 0.3 $\mathrm{cm}$ in diameter (Picture 2A). A blue-colored bleb with leakage of fluid to the diaphragmatic dome was identified when

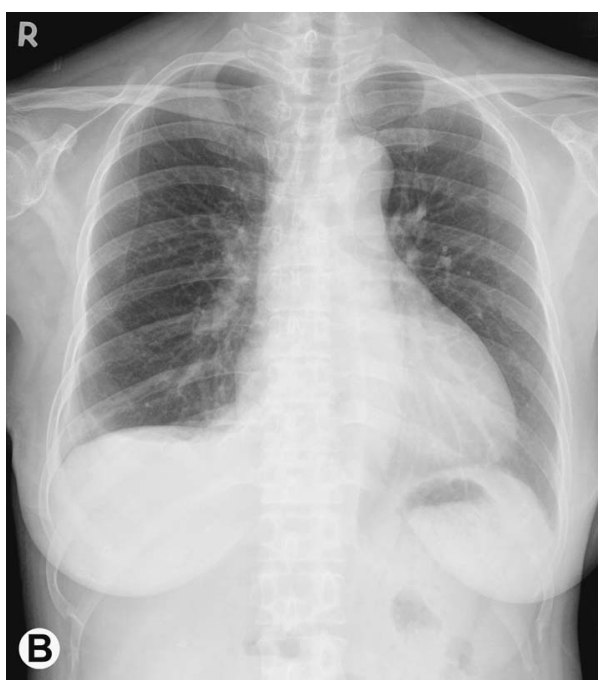

Picture 1B. Chest X-ray showing no right pleural effusion after video-assisted thoracoscopic surgery (VATS) three months follow-up. The arrow indicted a right diaphragm bleb sutured directly with a silk during the video-assisted thoracoscopic surgery (VATS).

we infused dialysate containing methylene blue. The diaphragm bleb was repaired by direct suture with a mesh and mechanical pleurodesis (Picture 2B). The postoperative course was smooth and CAPD was resumed after two weeks. On chest X-ray no recurrence of the pleural effusion was detected up to three months later (Picture 1B).

Hydrothorax is a result of pleuroperitoneal communication in approximately $2 \%$ of patients who undergo CAPD. The mechanism by which hydrothorax complicates peritoneal dialysis is still unclear, but it has been reported as a disorder of lymphatic drainage, a pleuro-peritoneal pressure

\footnotetext{
${ }^{1}$ Department of Internal Medicine, Tri-Service General Hospital, National Defense Medical Center, Taipei, Taiwan, Republic of China, ${ }^{2}$ Department of Surgery, Tri-Service General Hospital, National Defense Medical Center, Taipei, Taiwan, Republic of China and ${ }^{3}$ Department of Nurse, Tri-Service General Hospital, National Defense Medical Center, Taipei, Taiwan, Republic of China

Received for publication April 6, 2009; Accepted for publication April 8, 2009

Correspondence to Dr. Jen-Chih Chen, chen0828@kimo.com
} 


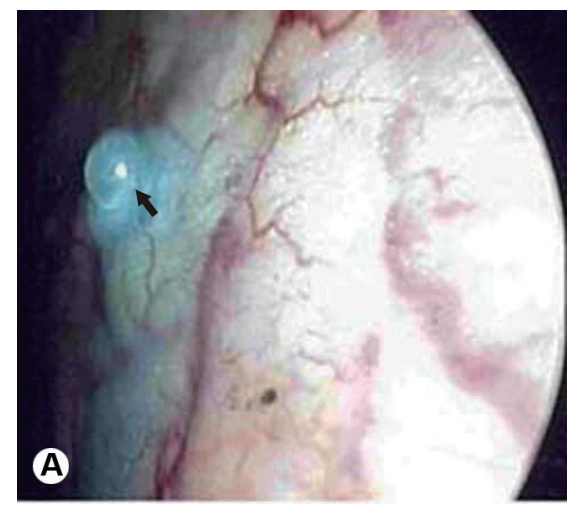

Picture 2A. A right diaphragm bleb about $0.3 \mathrm{~cm}$ in diameter during the video-assisted thoracoscopic surgery (VATS).

gradient, or a congenital diaphragmatic defect or bleb (1). The diagnostic tools are biochemical analysis (glucose, protein, and lactate dehydrogenase) of pleural fluid; direct visualization by methylene blue discoloration of the dialysate; and imaging studies including contrast computed to-

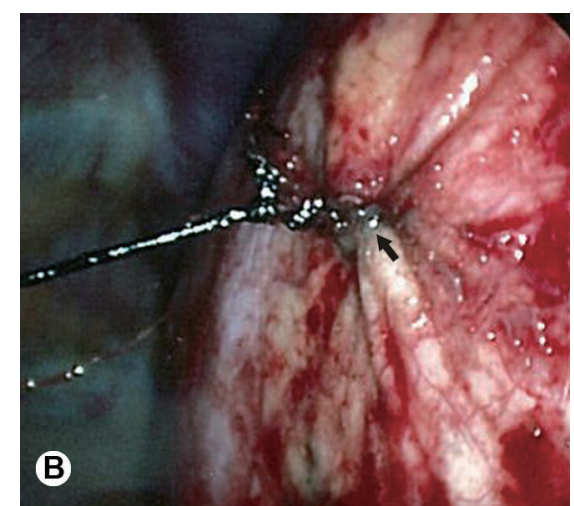

Picture 2B. Direct suture with a mesh during the video-assisted thoracoscopic surgery (VATS).

mographic peritoneography or peritoneopleural scintigraphy (2). The procedure of video-assisted thoracoscopic surgery and pleurodesis is effective and safe without recurrence on long-term follow-up for maintenance of peritoneal dialysis in acute hydrothorax complicating peritoneal dialysis (3).

\section{References}

1. Szeto CC, Chow KM. Pathogenesis and management of hydrothorax complicating peritoneal dialysis. Curr Opin Pulm Med 10: 315-319, 2004.

2. Tang S, Chui WH, Tang AW, et al. Video-assisted thoracoscopic talc pleurodesis is effective for maintenance of peritoneal dialysis in acute hydrothorax complicating peritoneal dialysis. Nephrol
Dial Transplant 18: 804-808, 2003.

3. Mak SK, Nyunt K, Wong PN, et al. Long-term follow-up of thoracoscopic pleurodesis for hydrothorax complicating peritoneal dialysis. Ann Thorac Surg 74: 218-221, 2002.

(C) 2009 The Japanese Society of Internal Medicine http://www.naika.or.jp/imindex.html 